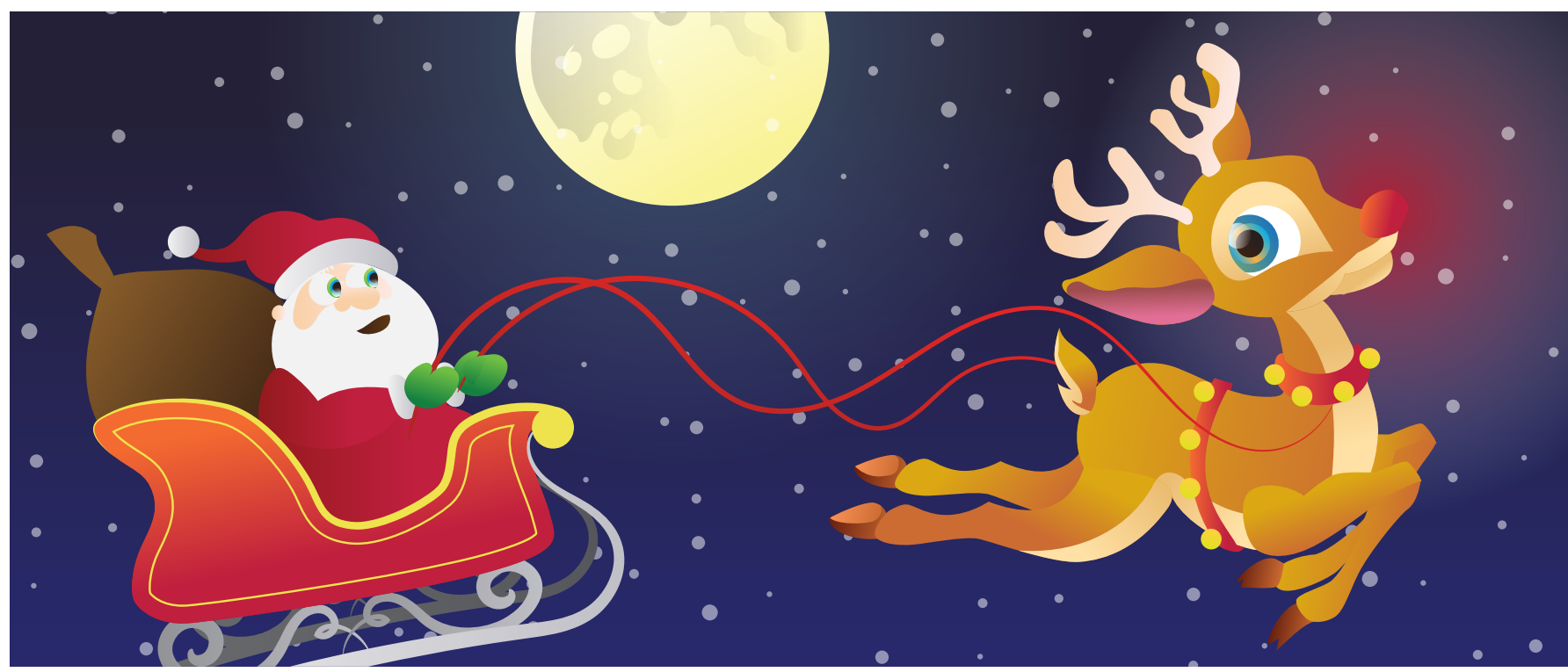

\title{
REINDEER VISION EXPLAINS THE BENEFITS OF A GLOWING NOSE
}

\section{Nathaniel J. Dominy ${ }^{1,2 *}$}

${ }^{1}$ Department of Anthropology, Dartmouth College, Hanover, NH, USA, ${ }^{2}$ Department of Biological Sciences, Dartmouth College, Hanover, NH, USA

\section{REVIEWED BY:}

CAROLINE 13 YEARS OLD
Arctic reindeer have unusual eyes and vision. In contrast to most mammals, reindeer can see ultraviolet light, which is invisible to us. They also have a reflective tissue in the eye that changes from a golden color during the summer months to a deep blue color during the winter months. Together, these special traits help reindeer see plant foods or predators in the snow, especially during the winter, when daylight in the Arctic is dim and purplish. A problem with being able to see purples and blues really well is that these colors are practically invisible in fog. Red light travels best in fog, and it follows that reindeer, more than other mammals, would benefit from a nose that produces red light. At least one reindeer is reported to have a luminescent (glowing) nose that operates well under foggy conditions. The goal of this paper is to estimate the redness of this nose and to explore its advantages and disadvantages.

\section{INTRODUCTION}

Rudolph the Red-Nosed Reindeer is a classic story of animal behavior by Robert L. May [1]. It describes reindeer disporting themselves (the 


\section{LUMINESCENT}

Emitting light; glowing.

\section{ULTRAVIOLET}

A type of light that is invisible to people but visible to some animals. For example, many birds and insects can see ultraviolet light.

\section{FIGURE 1}

Robert L. May's original notes from his reindeer observations were written in a poetic style called anapestic tetrameter. His notebook included sketches by Denver L. Gillen and this page illustrates the red glow or luminescence of

Rudolph's red nose under dark and drear atmospheric conditions (reproduced with permission of the Rauner Special Collections Library, Dartmouth College). technical term for playing games) and excluding a group member named Rudolph because of his unusually large, red nose. The light from Rudolph's nose, which May described as "dazzling" in daylight and "glowing" at night, later proved helpful on Christmas Eve, when thick Arctic fog disrupted the flight preparations of Santa Claus and his team of eight reindeer. Under these foggy conditions, Rudolph's nose emitted sufficient light for safe flight and the delivery of gifts around the world (Figure 1). This story of Rudolph's nose and its brilliance in fog is familiar to most children, adults, and biologists, but it is also considered to be anomalous, which means extremely unusual. As a general rule, scientists avoid studying anomalous traits. The fact that luminescent (glowing) noses are so rare explains why the color and advantages/disadvantages of luminescent noses are practically unstudied.

New findings about the color vision of reindeer could hold important clues about the value of a luminescent nose. For example, it was discovered recently that Arctic reindeer (scientific name Rangifer tarandus tarandus) can see ultraviolet (UV) light [2], which is invisible to humans and most other mammals that are primarily active in the daytime. The benefits of UV vision are unknown, but the ability to see UV light could help reindeer to see important things, such as predators and food. For example, the white fur of wolves and some important plant foods, such as lichens, absorb UV light, making the lichens look dark, and easier to see in snow, because snow reflects UV light and looks bright [3]. The benefits of seeing UV light could be greatest in the middle of winter, when the sun is low in the Arctic sky

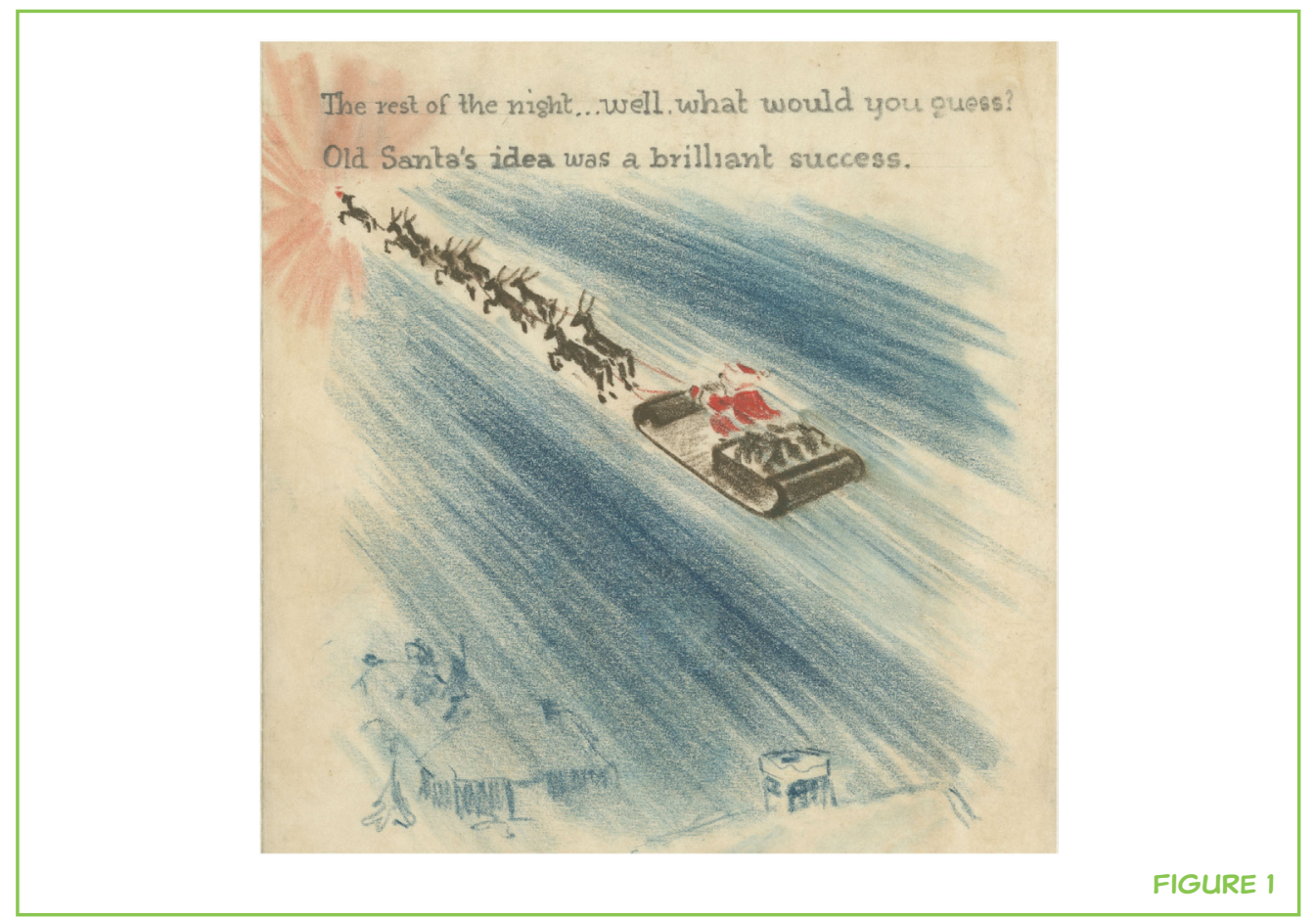


TAPETUM LUCIDUM

A mirror-like reflective tissue in the eyes of some animals that causes their eyes to shine when bright light hits them.

\section{MIE SCATTERING}

A process named after Gustav Mie, a German professor of physics. It happens when round or spherical particles of certain sizes cause light to scatter. and the scattering of light high in the atmosphere produces light that is mainly UV and purplish [4].

Even more surprising is the ability of reindeer eyes to change color with the seasons. Reindeer eyes have a mirror-like reflective tissue called a tapetum lucidum, which is Latin for "bright tapestry." This tissue causes eye shine, a phenomenon that is most often seen when the headlights of our cars shine into the eyes of wild animals or household pets. A tapetum lucidum is important for nocturnal (night-active) animals, because it allows them to see in the dark. The outstanding thing about reindeer is that their tapetum lucidum changes from a rich golden color during the summer to a deep blue color during the winter [5]. The factors that cause this color change are understood, but the advantages, if any, are mysterious. One idea is that it might increase the ability of reindeer to see blue light under dim light conditions. So, it is clear that Arctic reindeer have a highly unusual and interesting kind of vision. But, at the same time, this special ability to see blue light in late December is a definite disadvantage under foggy conditions.

\section{LIGHT TRANSMISSION IN FOG}

Fog is an accumulation of tiny water droplets or ice crystals suspended above the surface of the Earth. It forms when moist air is cooled below a specific temperature and some of the water vapor condenses (turns to tiny liquid droplets). By definition, the weather is considered foggy when we cannot see more than $1000 \mathrm{~m}$ ahead. In his book, Robert L. May [1] described fog "as thick as white fizz" and near zero visibility (it was "dark and drear"), which suggests that the fog could have been one of two possible types: radiation fog or ice fog. Radiation fog happens when the ground cools the air above it by contact. Ice fog occurs when warm air interacts with extremely cold air and the water vapor changes directly into a solid, forming tiny ice crystals suspended in the air.

The ability of light to shine through fog varies according to the color of light. Redder light travels farthest, but the distance that light can travel decreases if the size of the ice crystals or water droplets in the fog is large [6]. If the droplets are above a certain size, then a process called Mie scattering will extinguish all light of any color [7]. Mie scattering happens in most fog types, making most fog very difficult to see through, but a glowing red nose is predicted to outshine any other kind of nose, with red light traveling further in ice fog because the ice crystals in ice fog are smaller than the water droplets in radiation fog $[8,9]$. To understand how helpful Rudolph's nose might be in the fog, it is necessary to know the exact color of the light shining from his nose. 


\section{THE COLOR OF RUDOLPH'S NOSE}

A clue to the color of Rudolph's nose comes from Barbara Hazen's version of May's original story [10]. In this version, Rudolph hides behind a holly bush so that "his bright red nose blended in with the bright red berries." Figure 2 illustrates this event and the amount of light of each wavelength, which is a way of measuring the color, that bounces, or reflects, from holly berries. This type of graph is called a reflectance spectrum. If we assume that the berries shown in Figure 2 are similar to those of holly fruits in the Arctic, then we can estimate that Rudolph's nose produces light with a spectral peak of about 700 $\mathrm{nm}$, since this is the wavelength of light reflected most strongly by the holly berries. A peak reflectance of $700 \mathrm{~nm}$ means that the berries, and therefore Rudolph's nose, must be extremely red - possibly the maximum redness that the eyes of mammals are able to see.

This estimate is only an educated guess, but it does suggest that a red fog light is better than any other kind. Rudolph's nose may be especially important in winter, when the eyes of reindeer are better at seeing blue. Because fog blocks blue light, it makes sense that reindeer have the greatest need for a fog light in winter months like December. This helps to explain why Rudolph's nose was so useful for flying in thick fog. However, a luminescent red nose may have disadvantages, too. The noses of reindeer have a complex system of many tiny blood vessels [11] and are therefore quite warm [12], a trait that not only prevents reindeer noses from freezing but also causes heat from a reindeer's body to be lost to the surrounding air. If too much heat is lost from his glowing nose, Rudolph could risk hypothermia (a dangerously low body temperature) under extremely cold weather conditions. It is therefore extremely important for children to provide high-calorie foods to help Rudolph maintain his body temperature on Christmas Eve.

A later version of Rudolph the Red-Nosed Reindeer [10] discussed the similar color of ripe holly berries and Rudolph's nose.

The illustration by Richard M. Scarry is shown, together with an image of ripe holly fruits (common name: English / Christmas holly; scientific name: llex aquifolium). The graph shows the reflectance spectra of the berries, which basically describes the redness and brightness of their color. The red-shaded region represents the variation and the black line represents the average in a sample of 10 berries.
Overall, the advantages of a red luminescent nose appear to be greater than the disadvantages, which raises questions about how often red luminescent noses occur in reindeer. Currently, we know of only one luminescent nose in

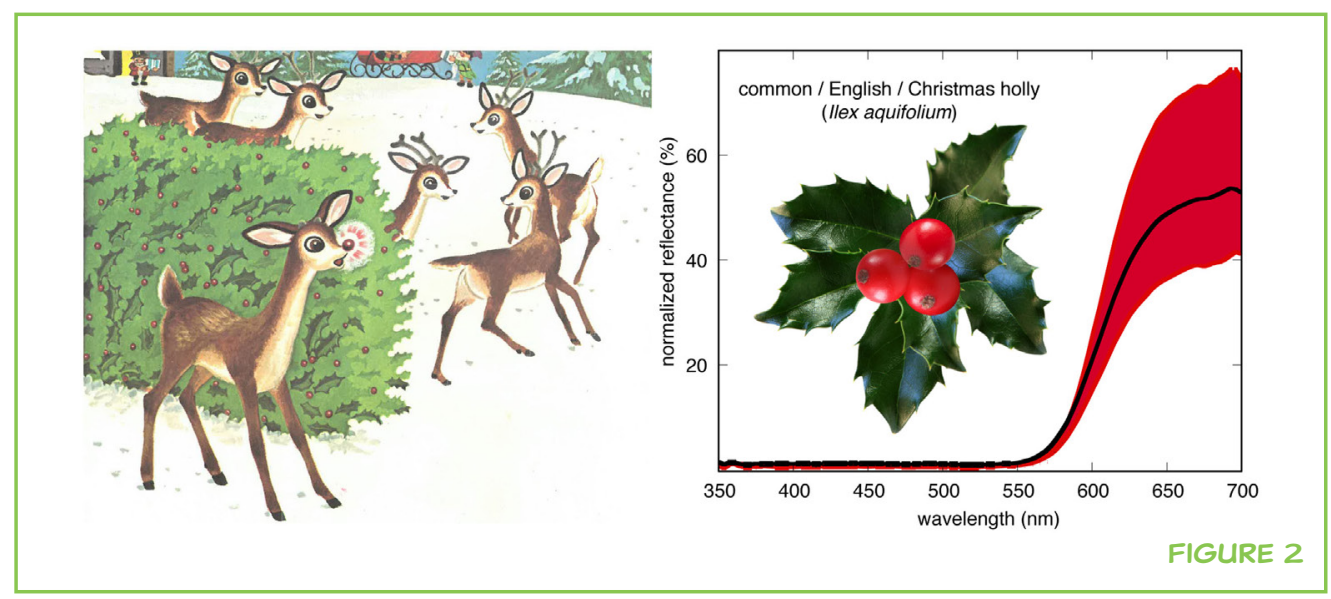


the reindeer population, but its advantages suggest that it could be passed on to future generations of reindeer. On the other hand, the frequency of foggy weather is decreasing worldwide due to climate changes [13], which may make the benefits of a glowing red nose less important in the future. A different hypothesis suggests that Rudolph's red nose is infected with nasal parasites and simply red and swollen [14]. Such different ideas about why Rudolph's nose is red tell us that further investigation is needed, and it is hoped that the readers of this article will help with future research on the properties of Arctic light and fog. Such studies could shed new light on the amazing biology and vision of reindeer.

\section{ACKNOWLEDGEMENTS}

I am grateful for the archival assistance of J. D. Shaw, M. R. Swan, A. L. Witzel, and staff of the Rauner Special Collections Library, Dartmouth College. I am indebted to the May family for facilitating and permitting the reproduction of Rudolph images. The views and research presented here were inspired by my daughter Eleanor, who likes to ask why.

\section{FUNDING}

Funding was received from the David and Lucile Packard Foundation (Fellowship in Science and Engineering no. 2007-31754).

\section{REFERENCES}

1. May, R. L. 1939. Rudolph the Red-Nosed Reindeer. Chicago, IL: Montgomery Ward.

2. Hogg, C., Neveu, M., Stokkan, K.-A., Folkow, L., Cottrill, P., Douglas, R., et al. 2011. Arctic reindeer extend their visual range into the ultraviolet. J. Exp. Biol. 214:2014-9. doi: 10.1242/jeb.053553

3. Meinander, O., Kontu, A., Lakkala, K., Heikkilä, A., Ylianttila, L., and Toikka, M. 2008. Diurnal variations in the UV albedo of arctic snow. Atmos. Chem. Phys. 8:6551-63. doi: 10.5194/acp-8-6551-2008

4. Tyler, N. J. C., Jeffery, G., Hogg, C. R., and Stokkan, K.-A. 2014. Ultraviolet vision may enhance the ability of reindeer to discriminate plants in snow. Arctic 67:159-66. doi: 10.14430/arctic4381

5. Stokkan, K.-A., Folkow, L., Dukes, J., Neveu, M., Hogg, C., Siefken, S., et al. 2013. Shifting mirrors: adaptive changes in retinal reflections to winter darkness in Arctic reindeer. Proc. R. Soc. Lond. B 280:20132451. doi: 10.1098/ rspb.2013.2451 
6. Arnulf, A., Bricard, J., Curé, E., and Véret, C. 1957. Transmission by haze and fog in the spectral region 0.35 to 10 microns. J. Opt. Soc. Am. 47:491-8. doi: 10.1364/ josa.47.000491

7. Grabner, M., and Kvicera, V. 2011. The wavelength dependent model of extinction in fog and haze for free space optical communication. Opt. Express 19:3379-86. doi: 10.1364/oe.19.003379

8. Kumai, M. 1973. Arctic fog droplet size distribution and its effect on light attenuation. J. Atmos. Sci. 30:635-43. doi:

10.1175/1520-0469(1973)030<0635:AFDSDA>2.0.CO;2

9. Price, J. 2011. Radiation fog. Part I: observations of stability and drop size distributions. Boundary-Layer Meteorol. 139:167-91. doi: 10.1007/s10546-0109580-2

10. Hazen, B. S. 1958. Rudolph the Red-Nosed Reindeer. New York, NY: Golden Press.

11. van der Hoven, B., Klijn, E., van Genderen, M., Schaftenaar, W., de Vogel, L. L., van Duijn, D., et al. 2012. Microcirculatory investigations of nasal mucosa in reindeer Rangifer tarandus (Mammalia, Artiodactyla, Cervidae): Rudolph's nose was overheated. Deinsea 15:37-46. Available from: http://www.hetnatuurhistorisch.nl/ fileadmin/user_upload/documents-nmr/Publicaties/Deinsea/Deinsea_15/DSA15_ Hoven_et_al.pdf

12. Ince, C., van Kuijen, A.-M., Milstein, D. M. J., Yürük, K., Folkow, L. P., Fokkens, W. J., et al. 2012. Why Rudolph's nose is red: observational study. BMJ 345:e8311. doi: 10.1136/bmj.e8311

13. Torregrosa, A., O'Brien, T. A., and Faloona, I. C. 2014. Coastal fog, climate change, and the environment. Eos Trans. Am. Geophys. Union 95:473-4. doi: 10.1002/2014EO500001

14. Halvorsen, O. 1986. Epidemiology of reindeer parasites. Parasitol. Today 2:334-9. doi: 10.1016/0169-4758(86)90053-0

SUBMITTED: 12 December 2015; ACCEPTED: 16 December 2015; PUBLISHED ONLINE: 21 December 2015.

EDITED BY: Silvia A. Bunge, University of California, Berkeley, USA.

CITATION: Dominy NJ (2015) Reindeer Vision Explains the Benefits of a Glowing Nose. Front. Young Minds 3:18. doi:10.3389/frym.2015.00018

COPYRIGHT () 2015 Dominy. This is an open-access article distributed under the terms of the Creative Commons Attribution License (CC BY). The use, distribution or reproduction in other forums is permitted, provided the original author(s) or licensor are credited and that the original publication in this journal is cited, in accordance with accepted academic practice. No use, distribution or reproduction is permitted which does not comply with these terms. 


\section{REVIEWED BY:}

\section{CAROLINE, 13 YEARS OLD}

My name is Caroline. I am 13 and in 7th grade. My favorite color is green and my favorite number is 36 . In my free time, I enjoy reading, art, yoga, photography, helping my community, and playing the drums.

\section{AUTHOR}

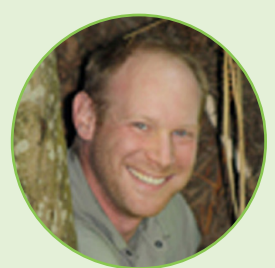

\section{NATHANIEL J. DOMINY*}

I am interested in plants and animals, especially primates, which include humans, apes, and monkeys. My job as a professor is to ask and explore questions about how primates find edible food, how they digest it, and how eating food affects their behavior and survival. I think that studying this process may help us understand why our bodies are so different from other animals. So, I spend a lot of time watching primates eat stuff in Central America, Africa, and Southeast Asia. It is really a fun job. When I am not working, I am with my two children, Eleanor, age 4, and Emerson, age 2. I also like to read about natural history and travel.

*nathaniel.j.dominy@dartmouth.edu 